\title{
Factors influencing the adoption of pre-harvest practices among mango farmers in Embu and Machakos counties, Kenya
}

\section{Antony Bundi*, John Mburu and Stephen G. Mbogoh}

Department of Agricultural Economics, University of Nairobi, P.O. Box 29053, 00625, Nairobi, Kenya Email: mwirigiantony@gmail.com Email:jmburu@yahoo.com Email: steve2008sgm@yahoo.com

*Corresponding author

\section{Jane L. Ambuko}

Department of Plant Science and Crop Protection, University of Nairobi, P.O. Box 29053, 00625, Nairobi, Kenya

Email: ambuko@yahoo.com

\begin{abstract}
Pre-harvest practices (PHPs) are key to sustainable mango farming, including their impact on fruit quality at harvest and post-harvest longevity. However, the adoption of these practices is still below the expected levels for optimal production. This paper analyses the determinants of the extent of adoption of PHPs using cross-sectional data collected in Embu and Machakos counties of Kenya. Multivariate probit and ordered probit models were applied. The results reveal that there are significant correlations among the PHPs. Further analysis shows that the probability of and the level of adoption of PHPs is influenced by region, years of experience in mango farming, off-farm income, mango sales, number of mango trees, access to inputs, and perceptions towards PHPs. These results indicate that policymakers and their development counterparts ought to strengthen farmers' access to farm inputs and extension services, and address barriers to financial access to accelerate the adoption of PHPs.
\end{abstract}

Keywords: mango; pre-harvest practices; PHPs; post-harvest losses; adoption; ordered probit; multivariate probit; MVP; Kenya.

Reference to this paper should be made as follows: Bundi, A., Mburu, J., Mbogoh, S.G. and Ambuko, J.L. (2020) 'Factors influencing the adoption of pre-harvest practices among mango farmers in Embu and Machakos counties, Kenya', Int. J. Postharvest Technology and Innovation, Vol. 7, No. 1, pp.56-72. 
Biographical notes: Antony Bundi is a student researcher at the University of Nairobi, at the final stages of completing his Master's in Agricultural and Applied Economics. He holds a Bachelor in Agribusiness Management (Kenyatta University). His research interests focus on technology adoption, commodity value chains, pre-and post-harvest management and impact studies. $\mathrm{He}$ is currently looking to finalise his studies and join the field of agricultural economics as a researcher and policy analyst.

John Mburu is the Chairman of the Department of Agricultural Economics, University of Nairobi, Kenya. He holds a $\mathrm{PhD}$ and Master in Agricultural Economics from the University of Goettingen, Germany. He has worked for over 17 years in areas of participatory impact assessment, monitoring and evaluation, cost-benefit analysis, conservation of biodiversity and natural resources, markets and value chain analysis, climate change, cross border trade, microfinance, and commodity value chain analysis. He has widely published in these areas. He is the Regional Chairman of the Pan African Consulting Consortium and Institute and a member of the AAAE, IASC, ISEE and ASEE.

Stephen G. Mbogoh is an Agricultural Economist by profession and a University Professor. He is currently involved in teaching, research and supervision of both undergraduate and graduate students in the Department of Agricultural Economics at the University of Nairobi. He also consults widely in assignments relevant to his area of professional expertise. He is a holder of Bachelor in Agriculture, Master and Doctoral in Agricultural Economics. He has over 40 years of professional experience in agricultural, livestock and resource development economics. He has published over 60 papers and scholarly articles in reputable peer-refereed journals and book chapters.

Jane L. Ambuko is an Associate Professor and Head of Horticulture Unit at the Department of Plant Science and Crop Protection, University of Nairobi. She holds a BSc in Agriculture, MSc in Horticulture from University of Nairobi (Kenya) and a PhD in Agricultural Sciences (Pomology and Postharvest Major) from Tsukuba University (Japan). Her area of specialisation is postharvest science and technology. She has published widely in internationally referred journals, received prestigious fellowships and is a member of several professional associations. She is a champion of Postharvest Loss Reduction aimed towards halving postharvest losses under Malabo Declaration (2014) and United Nation's SDG 12.3.

\section{Introduction}

\subsection{Background}

Agriculture offers the key to the attainment of multiple sustainable development goals (SDGs), notably zero hunger and no poverty, through the sustainable utilisation of the available land and the adoption of sustainable agricultural practices (FAO, 2018). The Food and Agriculture Organization of the United Nations (FAO) notes that approximately 1.3 billion tonnes (USD 750 billion) of food is lost or wasted along the supply chain. This is in spite of the approximately 815 million people facing hunger and even more of them who are malnourished. This reflects an inefficient food system. 
To feed the rising global population, agriculture production and productivity ought to increase by $50-70 \%$ by the year 2050 . However, this goal is challenged by the declining potential of the natural resources necessary for agricultural production, a problem that is exacerbated by the effects of climate change (FAO, 2011; World Bank, 2011). Nevertheless, through SDG 12 on responsible production and consumption, experts in food security have identified the reduction in food losses and waste as a way of enhancing food availability. The reduction of post-harvest losses is noted as one way of achieving increased food availability, and pre-harvest practices (PHPs) play a key role.

As noted by Rehman et al. (2015) knowledge of the interactions between pre-harvest and post-harvest systems in fruits farming is important in understanding the basis for variability in fruit quality after harvest. Horticultural crops, especially fruits and vegetables, exhibit high post-harvest losses due to their perishability and fragile nature.

In Kenya, the horticulture sub-sector is the third most important contributor to gross domestic product (GDP), with fruits contributing to $27 \%$ of the value of horticultural produce (Republic of Kenya, 2016). Mango (Mangifera Indica) was ranked as the second most important fruit contributing to $21 \%$ of the value of fruits, second after banana. However, $25-45 \%$ of mangoes are lost along the value chain, with a high percentage of loss arising from production-related issues, such as pests and diseases (Affognon et al., 2013).

A growing body of literature has in the past focused on ways of minimising food losses and specifically post-harvest food losses. However, research has uncovered the need to understand the pre-harvest factors and interventions that influence post-harvest behaviour and quality of crops (Ferguson et al., 1999; Fiaz et al., 2016; Hewett, 2006; Manganaris, 2008). Normally, crop damages occur in the field before harvesting due to physical, environmental or biological factors that manifest in the produce much later after harvesting hence leading to losses (Florkowski et al., 2009; Thompson, 2007).

\subsection{Pre-harvest practices}

A pre-harvest system entails all existing technologies/practices for agricultural production. It thus includes the technical and economic relations within agriculture including choice of cultivar, environmental factors, cultural practices (irrigation and fertiliser application, thinning, protective measures) and fruit maturity (Rehman et al., 2015). This study focused on cultural practices, notably water conservation and management, organic and inorganic fertiliser management, and thinning.

Water conservation and management is crucial in ensuring ideal photosynthesis, plant growth, the strength of the tree, uptake of crucial minerals and quality yields in fruits (Hewett, 2006). Water management is crucial also because excess water leads to waterlogging and root rot whereas too little water causes stress in plants and stunted growth.

Mineral nutrients, from organic and inorganic fertilisers, applied in sufficient quantities and at the right time, play a crucial role in plant nourishment, improves production and deters disease severity (Chowdhury and Rahim, 2007; Ferguson and Boyd, 2002). Nutritional imbalances, either excess or deficiency, affect fruit quality and post-harvest disorders.

Thinning is crucial for reducing the vegetation of the mango tree and thus resulting in light penetration, greater aeration, and reduced nutrient competition. These lead to good 
fruit colour, better quality fruits and reduced disease incidence (Engels et al., 2009; Maqbool and Mazhar, 2007).

From past research findings (Ferguson et al., 1999; Hewett, 2006; Maqbool and Mazhar, 2007; Rehman et al., 2015), it is evident that the availability of quality fruits is determined before harvest since harvesting deprives the fruit of its source of water and nutrients. This means that further improvement in fruit quality after harvest is not possible and all that can be done is to maintain the quality. Therefore, even with the best technologies and knowledge on post-harvest handling of crops, it is important to assess the pre-harvest factors and conditions that influence the post-harvest behaviour of fruits.

Past studies have dwelt on the adoption of single components, such as integrated pest management, yet farmers deal with overlapping constraints, such as low soil fertility, infestation by pest and diseases, low productivity and moisture stress on crops. Ideally, farmers adopt multiple practices, either as substitutes or complements, to deal with these challenges. Therefore, the approach of this study was to look at the PHPs as a bundle.

The objective of this study is therefore to provide an understanding of the factors influencing the adoption of multiple pre-harvest components, and intensity of adoption. The aim is to contribute to literature and guide in designing policies that stimulate increased adoption of PHPs to curb post-harvest losses.

\section{Methodology}

\subsection{Conceptual framework}

The conceptual framework shown in Figure 1 shows the relationships between the factors that are hypothesised to influence the adoption of PHPs. Demographic, institutional, and farm characteristics are hypothesised to influence the farmer's perceptions and the adoption of PHPs. The farmers' perceptions in turn influence the farmers' decision to adopt the PHPs. If a farmer adopts the practices, it is hypothesised that he/she will gain from reduced mango losses, improved mango yields, and high-quality mango fruits thus realising higher income.

\subsection{Theoretical framework}

This study is grounded in the random utility framework. The explanatory variable, which is ordinal in nature, indicated as zero $(\mathrm{Pi}=0)$, one $(\mathrm{Pi}=1)$, two $(\mathrm{Pi}=2)$, three $(\mathrm{Pi}=3)$, or four $(\mathrm{Pi}=4)$ if the farmer adopts zero, one, two, three or four PHPs. Farmers are presumed to adopt a given number of practices, based on the level of utility attained whilst maximising the utility function.

$$
U_{i}=V_{i}\left(\beta X_{i}\right)+u_{i} \text { for } i=1, \ldots ., n
$$

where

$U_{i}$ the observed portion of the farmer's utility function

$X_{i} \quad$ is expressed as a vector of exogenous socio-demographic and institutional factors

$\beta \quad$ vector of parameters to be estimated 
$u_{i} \quad$ the unobserved portion of the utility framework, that is the random error term.

The farmer chooses to adopt an additional PHP if the utility gained is greater than the utility of non-adoption. Although the level of utility of individual farmers cannot be observed, it is noted that:

$$
\begin{aligned}
& P_{i}=0 \text { if } U_{i} \leq \alpha_{1} \\
& P_{i}=1 \text { if } \alpha_{1}<U_{i} \leq \alpha_{2} \\
& P_{i}=2 \text { if } \alpha_{2}<U_{i} \leq \alpha_{3} \\
& P_{i}=3 \text { if } \alpha_{3}<U_{i} \leq \alpha_{4} \\
& P_{i}=4 \text { if } U_{i}>\alpha_{4}
\end{aligned}
$$

where $\alpha_{1}<\alpha_{2}<\alpha_{3}<\alpha_{4}$ are unknown threshold parameters to be estimated by the $\beta$.

Figure 1 Conceptual framework illustrating the factors hypothesised to influence the adoption of PHPs

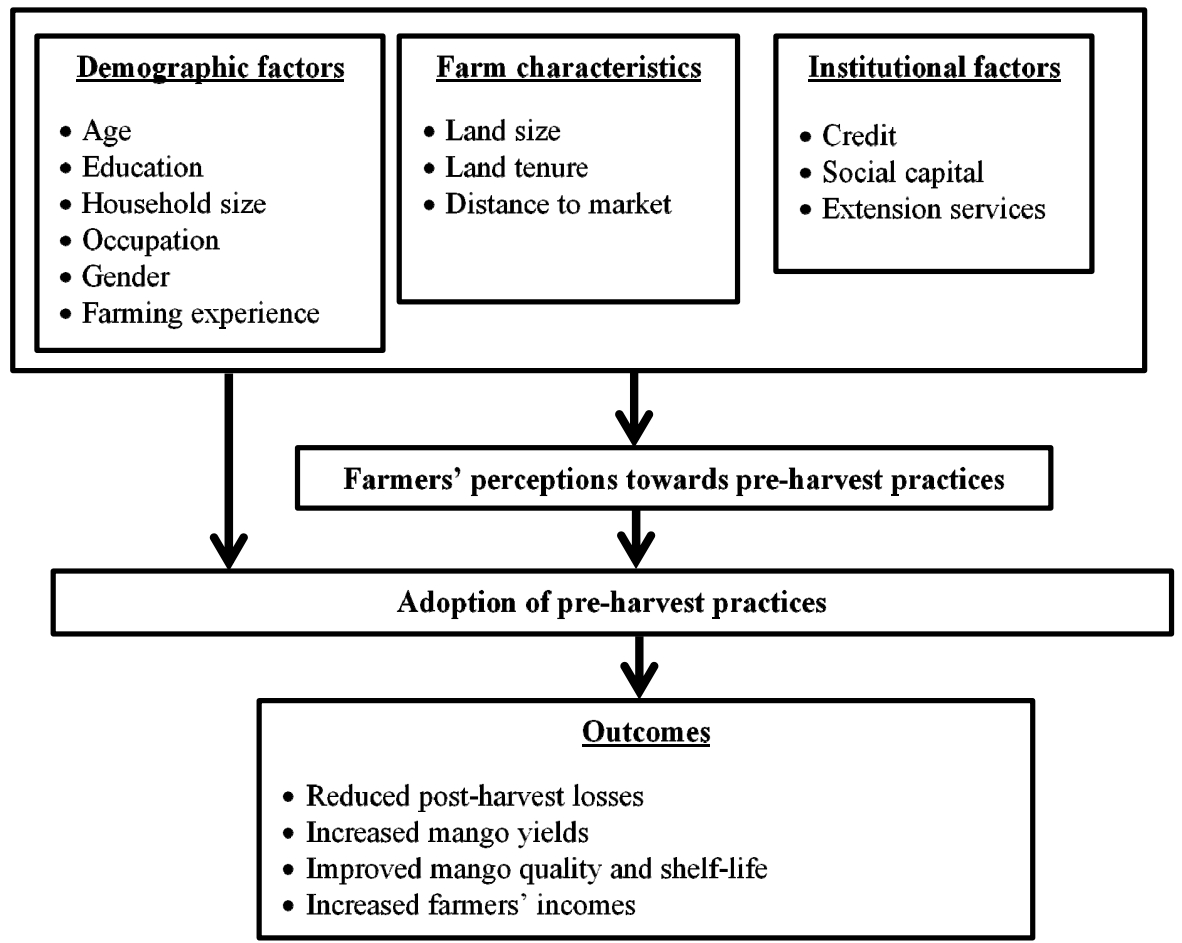

Source: Author's conceptualisation

\subsection{Analytical model}

This paper adopted two econometric specifications. First, the factors influencing multiple adoption decisions of the PHPs were modelled using a multivariate probit (MVP) model. Farmers adopt a set of practices to deal with overlapping problems at the farm level. This means that the adoption decision is multivariate so that there exists information on the interdependency of the adoption decisions. 
Unlike in the case of single adoption equations where the adoption decisions of the farmer are not interdependent, this study presents a case of multiple adoption decisions wherein the farmers' adoption decisions are interdependent. This calls for use of the MVP approach to examine the effect of a set of explanatory variables on each PHP. It accounts for a possible association between the error terms and also the interrelationships among the PHPs (Teklewold et al., 2013). Such interrelationships may arise from complementarities (positive correlation) and substitutability (negative correlation) between the different PHPs. Green (2008) notes that failure to capture these unobserved factors and interrelationships among adoption decisions regarding different practices would lead to the model estimates being biased and inefficient.

Secondly, the determinants of the number of PHPs adopted were modelled using an ordered probit model (OPM). The level of adoption of PHPs presents a case of multiple adoptions, whereby defining a cut-off point between the adopters and non-adopters is difficult (Wollni et al., 2010). In this study, the majority of farmers did not adopt all four practices. Therefore, there was the problem of quantifying the degree of adoption of the practices using the area under the practice as seen in adoption studies. However, Teklewold et al. (2013) and Wollni et al. (2010) overcame this challenge by using the number of practices adopted as the dependent variable in the model. This is in contrast to other past studies that treat the number of practices adopted as a count variable and make use of Poisson regression. While the Poisson regression model is best suited for count data, it is based on the assumption that the occurrence of all the events has the same probability (Wollni et al., 2010). This was not the case for this study since the probability of adopting one practice could differ from the probability of adopting two or three practices. Also, the utility derived from adoption is expected to increase as the number of practices adopted increases. Therefore, the number of PHPs adopted is an ordinal variable that necessitated the use of an ordered probit regression model in this study.

Therefore, the MVP model was used to elicit the factors influencing the probability of adoption of the PHPs while taking into account their interrelationships. The OPM was used to analyse the intensity of adoption of the PHPs.

\subsection{Study area and sampling}

This study was conducted in Embu and Machakos counties, Kenya. Specifically, Kyeni South Ward (Embu) and Mwala and Masii wards (Machakos) were selected as part of the yield wise project by The Rockefeller Foundation. A sampling frame was developed based on a household census that had been conducted with the help of village elders before the survey. With the desired sample size of 320 respondents, due to resource limitations, a systematic random sampling method was used to select households for this study, based on sampling intervals. The sample size was divided into 160 respondents in Embu (Kyeni South) and 160 in Machakos. For Machakos, the 160 respondents were apportioned into 107 in Mwala ward and 53 in Masii ward, based population proportions.

\subsection{Data collection and analysis}

A semi-structured questionnaire was administered to respondents, to gather qualitative and quantitative primary data from the two study counties between June and July 2018. Data was collected on household demographics, farm, and mango production-related 
information, as well as on producers' perceptions towards the PHPs. The data was analysed using the STATA v14.

\section{Results and discussion}

\subsection{Data and descriptive statistics}

Table 1 presents the descriptive statistics of the variables considered in the models. The dependent variables for the MVP model are the PHPs, taken as the farmers' adoption of the practices. Adoption rates were 38\% for water conservation and management, 54\% for manure application, 20\% for inorganic fertiliser application and 35\% for thinning.

For the OPM, the dependent variable was the number of PHPs a farmer adopted, taken as a count variable. The farmers adopted an average of 1.47 of the four practices, whereby $23 \%$ did not adopt any practice, $32.67 \%$ adopted one, $23.67 \%$ adopted two, $15.67 \%$ adopted three, and $5 \%$ adopted all the practices. Therefore, the majority of the respondents adopted at least one of the PHPs.

The independent variables for both models are classified into socio-demographic, institutional and farm characteristics. For the socio-demographic characteristics, the interviewed households were $82 \%$ male-headed; with an average formal education level of eight years of schooling and a mean age of 58 years. This means that the average household head had completed primary school education and that mango farming is practised by elderly persons. The dependency ratio was $57 \%$ which meant that more than half of households had a high number of children below 15 years and adults of over 65 years. Dependency ratio was used as a proxy for farm labour and resource availability. The respondents had practised mango farming for ten years on average and accumulated over KES 100,000 in off-farm income.

Concerning farm and production characteristics, the respondents had an average of 58 mango trees, with a range of 0-900 trees and hence were classified as small-holder farmers. The value of mango sales had a mean of KES. 43,109.14 based on prevailing market prices. Eighty-eight percent of the farmers intercropped mangoes with other crops, mainly maize and beans. At least $60 \%$ of the respondents had formal title to their land, with the average land accessed being four acres. Forty-six percent of the households kept livestock in their farms, which is a source of manure.

As for the institutional factors, $45 \%$ of respondents had received extension services or training, with the main subjects covered being good agronomic practices and farming as a business. Membership to groups was at $26 \%$ and only $5 \%$ had obtained credit in the period under consideration. Approximately $70 \%$ of farmers admitted to having faced constraints in accessing farm inputs, mainly due to high prices and unavailability when needed. The distance to the market had a mean of 5.37 kilometres. Only $10 \%$ of farmers had carried out soil tests, citing high cost and lack of information about soil tests.

Farmers' perceptions towards the PHPs were included in the model, following Mwangi and Kariuki (2015) who recommended inclusion of the perceptions that farmers have towards technology or practice, as a variable in the adoption model. Farmers' perceptions were elicited by way of a Likert scale whereby farmers expressed the most important benefit to the PHPs. The farmers perceived that water management was crucial for improving fruit quality while thinning was important in enhancing the colour of fruits. 
Besides, the application of farmyard manure and inorganic fertilisers was beneficial in increasing mango yields.

Table 1 Summary statistics of the variables used in the models

\begin{tabular}{|c|c|c|c|c|}
\hline Variable description & Mean & Std. dev. & Min & $\operatorname{Max}$ \\
\hline \multicolumn{5}{|l|}{ Continuous variables } \\
\hline Number of pre-harvest practices adopted & 1.47 & 1.15 & 0 & 4 \\
\hline Education level of household head (years) & 8.43 & 4.01 & 0 & 19 \\
\hline Age of household head (years) & 58.51 & 14.31 & 24 & 98 \\
\hline Dependency ratio & 0.57 & 0.73 & 0 & 5 \\
\hline Farming experience (years) & 10.06 & 6.40 & 0 & 41 \\
\hline Off-farm income (KES) & 100,362 & 167,964 & 0 & $1,400,000$ \\
\hline Mango trees (number) & 58.75 & 112.58 & 0 & 900 \\
\hline Mango sales (Ln) KES & 43,109 & 144,004 & 0 & $2,262,000$ \\
\hline Distance to market (Kms) & 5.37 & 6.22 & 0.05 & 50 \\
\hline Land size (acres) & 4.00 & 4.51 & 0.25 & 32 \\
\hline Discrete variables & Percent (\%) & & & \\
\hline Sex of household head (dummy $1=$ male) & 82.61 & & & \\
\hline Access to extension $(1=$ received extension $)$ & 45.34 & & & \\
\hline Region $(1=\mathrm{Embu})$ & 49.69 & & & \\
\hline Access to credit $(1=$ obtained $)$ & 5.28 & & & \\
\hline Group membership $(1=$ member $)$ & 26.71 & & & \\
\hline Practice intercropping $(1=$ yes $)$ & 88.33 & & & \\
\hline Keep livestock ( 1 = yes $)$ & 45.96 & & & \\
\hline Land ownership ( 1 = formal tenure $)$ & 60.67 & & & \\
\hline Input access ( $1=$ experience constraints $)$ & 69.67 & & & \\
\hline Practice pruning $(1=$ yes $)$ & 94.33 & & & \\
\hline Carried out soil tests $(1=$ yes $)$ & 10 & & & \\
\hline Water management & 38 & & & \\
\hline Organic fertiliser (manure) & 54 & & & \\
\hline Inorganic fertiliser & 20 & & & \\
\hline Thinning & 35 & & & \\
\hline
\end{tabular}

Source: Author's survey 2018

\subsection{PHP adoption decisions: MVP model results}

The MVP model generated a covariance matrix of the regression equations between the PHPs using the joint estimation approach as shown in Table 2. The likelihood ratio test $\left.\left[\mathrm{Chi}^{2}(6)=34.9408, \mathrm{p}=0.000\right)\right]$ of the null hypothesis that the covariance of the error terms across equations are not correlated was rejected. 
Table 2 Correlation coefficients for MVP regression equations

\begin{tabular}{lccc}
\hline & Manure $(M)$ & Fertiliser $(F)$ & Water $(W)$ \\
\hline Fertiliser (F) & $0.2725^{* *}(0.1288)$ & & \\
Water (W) & $0.3752^{* * *}(0.1136)$ & $0.4183^{* * *}(0.1156)$ & \\
Thinning (T) & $-0.1476(0.1103)$ & $0.1580(0.1118)$ & $0.2054 * *(0.0962)$ \\
\hline
\end{tabular}

Notes: Likelihood ratio test of: $\rho \mathrm{MF}=\rho \mathrm{MW}=\rho \mathrm{MT}=\rho \mathrm{FW}=\rho \mathrm{FT}=\rho \mathrm{WT}=0$. $\mathrm{Chi}^{2}(6)=34.9408 * * * . * * *, * *$ and $*$ denote statistical significance at $1 \%$, $5 \%$ and $10 \%$ respectively. Standard errors in parenthesis.

Source: Author's survey 2018

The results in Table 2 show that the estimated coefficients were statistically significant in four of the six pairs. The significant coefficients all have positive signs, indicating that MVP was suitable as a model and that the practices are interdependent. In this case, manure is complementary with fertiliser and water, while fertiliser is complementary with water and water is complementary with thinning. This complementarity among practices infers that a change in policy that affects one PHP is likely to have spillover effects on other PHPs.

Table 3 shows the results of the MVP model which was estimated using the maximum likelihood method on household observations. The model fitted the data well as shown by the Wald test [Wald $\left.\mathrm{chi}^{2}(58)=206.61, \mathrm{p}=0.000\right)$ ]. Therefore, the hypothesis that all regression coefficients are jointly equal to zero was rejected. In addition, the coefficients are substantially different across the equations. Therefore, it is concluded that differentiating the practices was appropriate.

Results from the MVP regression model indicate that the level of education of the household head negatively influences practising thinning. This means that more educated people did not practice thinning and this could be attributed to the fact that the majority of the respondents associated thinning to increased fruit losses.

The location of the farmers, where Embu County was selected as the reference, was shown to significantly influence manure and fertiliser application negatively. This meant that the farmers in Embu did not adopt these practices in their orchards as compared to their Machakos counterparts.

The years of farming experience in mangoes had a significant and positive influence on the adoption of irrigation and water conservation practices. This could be attributed to learning and past experiences on the benefits since they have dealt with mangoes for longer periods.

Households who had access to income outside of farming activities were more likely to adopt organic and inorganic fertilisers in their mango orchards. This is supported by Teklewold et al. (2013) whose findings are similar and argue that off-farm income enables farmers to purchase more inputs and to minimise risks.

The number of mango trees, taken as a proxy for farm size, had a positive and significant influence on manure application on the farm. Farmers with more mango trees had a higher probability of adopting farmyard manure application to their mango trees. Farm size, or number of mango trees in this case, has been shown to positively influence technology adoption (Mignouna et al., 2011). 
Table 3 Factors influencing the adoption of PHPs based on the MVP model

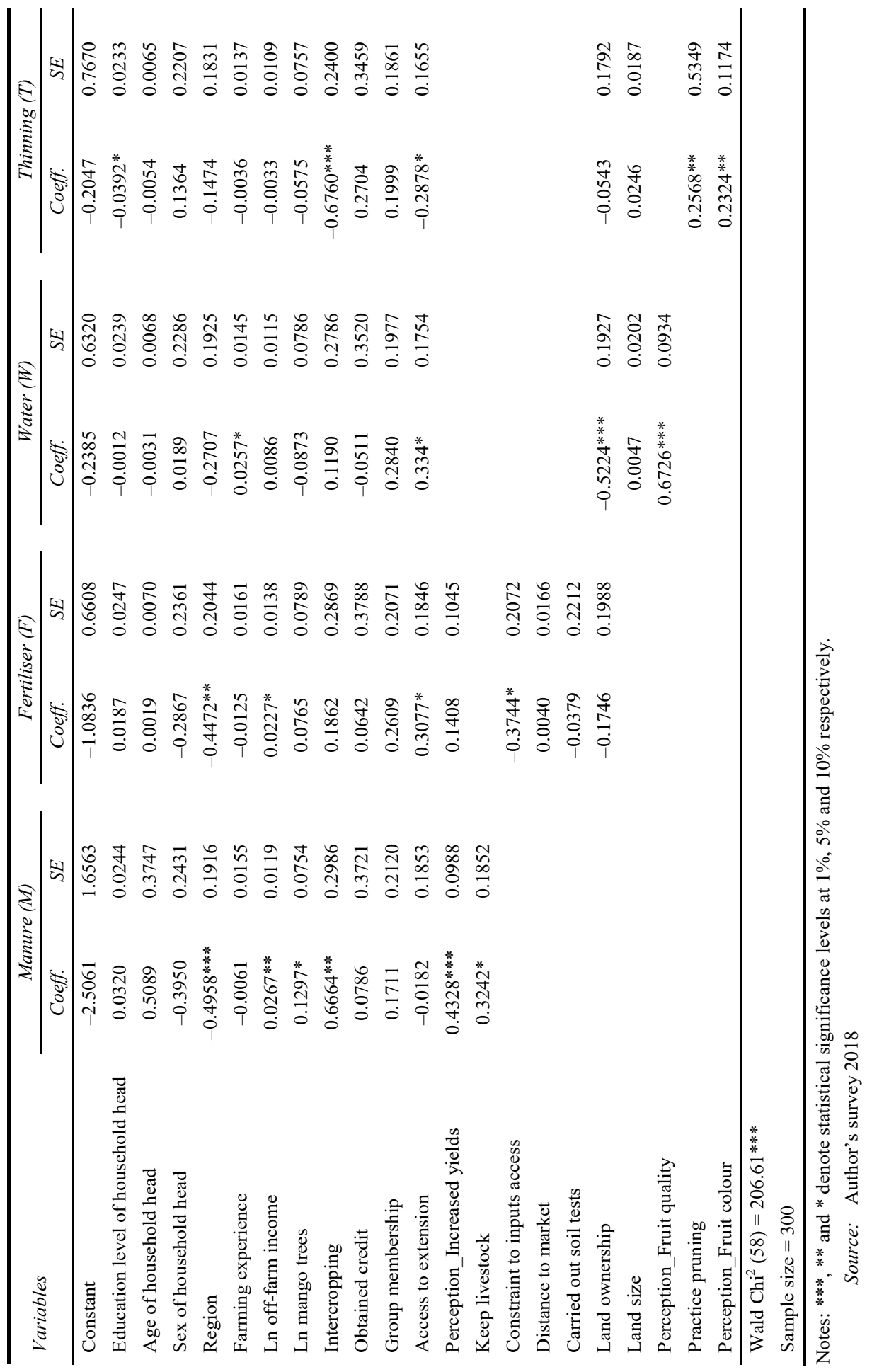


The practice of intercropping between mango trees with other crops had a significant positive effect on manure application but a negative influence on thinning. Farmers intercropped mangoes mainly with maize and beans. The farmers who intercropped mango trees with food crops adopted manure application as a way to increase the production of their intercrops simultaneously and avoid loss of farm area dedicated to mangoes.

Access to extension services was found to positively influence the adoption of inorganic fertilisers and water conservation and management practices. This result highlights the importance of extension services in promoting sustainable agricultural production practices, and is consistent with earlier studies by Arslan et al. (2013) and Teklewold et al. (2013). Thus, farmers get educated on the benefits of using chemical fertilisers, irrigating mango trees and applying moisture conservation techniques.

Farmers' perceptions towards the PHPs were added as explanatory variables for the adoption model. In this case, 'increased yields', 'improved fruit quality' and 'fruit colour enhancement' were the benefits associated with manure and fertiliser application, water conservation and management, and thinning practices respectively. The MVP model estimation showed that these farmers' perceptions positively influenced the adoption of the PHPs, implying that adoption is influenced by factors inherent to individual farmers such as their viewpoints on the benefits of an activity. As reported by Mignouna et al. (2011), farmers adopt technologies that are compatible with their needs.

Livestock ownership was found to positively influence the adoption of organic fertiliser in mango farming. Although an important source of manure, livestock competes with crop enterprises for labour and remnants of crops thus negatively influencing soil enhancement practices (Marenya and Barrett, 2007). However, Teklewold et al. (2013) established that livestock ownership positively influences the adoption of manure application, which offers similar results to this study.

Constraints to input access negatively impacted on fertiliser use, and this could be explained by the fact that fertiliser has to be externally sourced, unlike farmyard manure. The main constraint to inputs access as expressed by farmers was the high prices for the inputs that made them unaffordable. Land ownership (security of tenure) was found to negatively influence the adoption of water conservation and management. This result contradicted findings by Gebremariam and Wünscher (2016) who found that secure land tenure increases the investments in soil and water conservation. This could have been because water conservation and management was not a popular practice among mango farmers and the majority of them did not acknowledge its importance.

\subsection{Number of PHPs adopted: OPM results}

The results from the estimation of the OPM are given in Table 4, including the marginal effects. Variance inflation factor (VIF), a test for multi-collinearity, yielded a mean of 1.76 which shows that there was no problem of multi-collinearity. Following Gujarati (2006), if the VIF of a variable exceeds 10 , that variable is said to be highly collinear and can be excluded from the model. Secondly, the Breusch-Pagan/Cook-Weisberg test for heteroscedasticity yielded satisfactory results. The null hypothesis (Ho = constant variance) was thus rejected since there was no problem of heteroscedasticity.

The chi-squared statistic for the OPM is 150.63 and is statistically significant indicating that the joint test of all slope coefficients being equal to zero is rejected. The 
pseudo- $\mathrm{R}^{2}$ value was 0.1691 implying that $16.91 \%$ of variations in the number of PHPs adopted are explained by the independent variables included in the model.

The results reveal that the location of the farm, in which the default is Embu County, has a significant and negative effect on the number of PHPs adopted. Farmers in Embu this adopted fewer PHPs compared to their Machakos counterparts, implying spatial differences between the two regions.

The natural log of off-farm household income has a positive influence on the number of practices adopted. Access to off-farm income provides capital to purchase inputs and pay for labour, thus supporting the result. This is also supported by the income from mango sales which showed a positive effect on the number of PHPs adopted. Also, the farmers' perceptions of 'increased yields' and 'improved fruit quality' showed a positive impact on the number of PHPs adopted.

Many farmers expressed they had constraints in accessing agricultural inputs for mango production, especially due to the high costs that make them unaffordable. As a result, this constraint negatively impacted the number of PHPs adopted. Farmers who reared livestock in their farm adopted fewer PHPs. This could be explained by the labour intensity involved in livestock production which leads to more time being allocated to livestock at the expense of mango farming. The distance to input/output markets had a positive influence on adoption.

However, the coefficients of the ordered probit are not readily interpretable (Teklewold et al., 2013; Wollni et al., 2010). Rather, the marginal effects (as shown in Table 4) are of more interest since they show the changes in the dependent variable on the response to changes in explanatory variables. Marginal effects after the ordered probit ought to explain the magnitude by which a variable influences movement from zero to four practices by a farmer, since the goal is to adopt as many PHPs as possible.

The results of the marginal effects based on the ordered probit estimates are shown in Table 4. There were four practices in consideration with a mean of 1.47. The goal would be to adopt more practices since the higher the adoption the more the utility gained in increasing mango production, enhancing quality and reducing post-harvest losses. For this reason, this study assessed the factors that influence the adoption of more than two PHPs. The percentage increase or decrease was calculated by summing the marginal effects from $\mathrm{P}=2$ to $\mathrm{P}=4$.

The results indicate that as the dependency ratio increased, the probability of adopting more than two PHPs decreased by $8.74 \%$. In most developing countries, household members provide farm labour because they cannot afford waged labour (Marenya and Barrett, 2007). This result is also supported by Sheahan and Barrett (2014) who reported that the households with more dependents use more farm resources and have inadequate labour to employ on the farm. Besides, they are also constrained in terms of resources in terms of less money to spend on agricultural inputs.

Farmers expressed that 'increasing mango yields' was the primary objective of applying manure and fertiliser, while 'improving fruit quality' was the main purpose of water conservation and management. In turn, these perceptions were shown to increase the probability of adopting more than two PHPs by $7.73 \%$ and $6.85 \%$ respectively. Consistent with studies by Reimer et al. (2012) and Meijer et al. (2015) the way farmers perceive certain practices or technology attributes is crucial in influencing their adoption decisions. 
Table 4 Factors influencing the number of PHPs adopted (ordered probit)

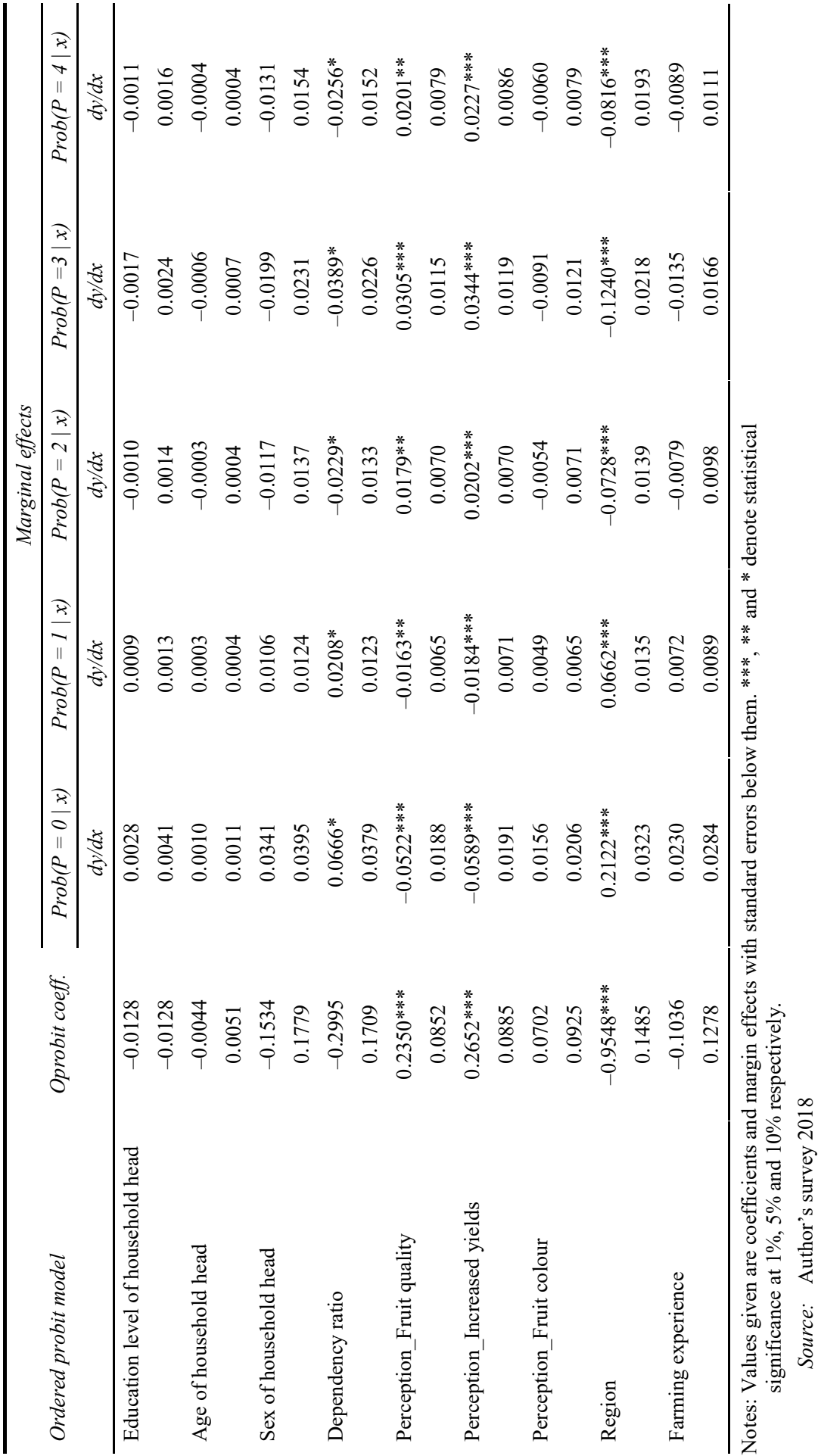


Table 4 Factors influencing the number of PHPs adopted (ordered probit) (continued)

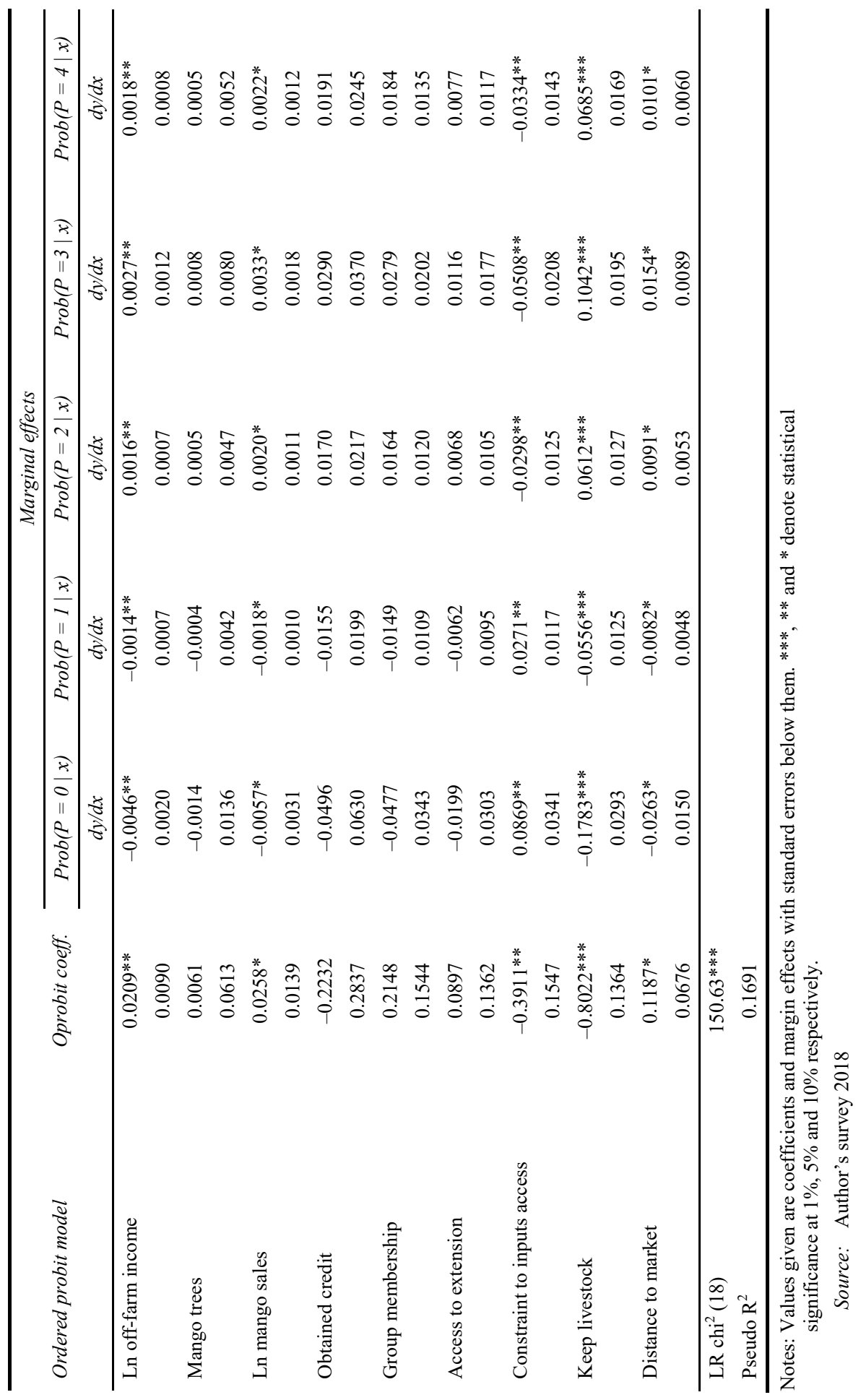


Regarding region, if the household is located in Embu County, the probability of adopting more than two PHPs decreases by $3.02 \%$. This means that farmers in Embu are less likely to adopt more than two PHPs when compared to their Machakos counterparts. Results from the MVP support this result since it was found that adoption rates in Embu are lower than in Machakos. This could be attributed to the importance placed on mangoes when both regions are compared. Embu, a higher agricultural potential region, has more economic activity and less reliance on mangoes when compared to Machakos.

The availability of off-farm income has a positive marginal probability effect $(0.61 \%)$ on the adoption of more than two PHPs. An increase in off-farm income for a household leads to the adoption of more PHPs. Availability of off-farm income (salary, remittances business or pension) provides capital for purchasing farm inputs or paying for labour. This is the same for mango sales, whereby an increase in revenue earned from mangoes increased the probability of adopting more than two PHPs by $0.75 \%$. Such income can be ploughed back for the development of the farm and act as a motivator for proper care of the orchard.

Access to farm inputs was assessed to determine whether the household had constraints in accessing inputs required in mango production. If a household had experienced constraints in accessing farm inputs, the probability of adopting more than two PHPs decreased by $11.41 \%$. The most cited constraints were high prices and unavailability of inputs when needed.

Ownership of livestock gave a positive influence on the number of PHPs adopted. If a household reared livestock, the probability of adopting more than two PHPs increased by 23.39\%. Consistent with other studies (Marenya and Barrett, 2007; Teklewold et al., 2013), livestock ownership is the single most important source of manure. Livestock is also a source of draft power to fetch water or take produce to the market.

Finally, an increase in the distance to the market by one kilometre was shown to increase the probability of adopting more than two PHPs. Farmers who are furthest from the market could be motivated to adopt more PHPs to improve fruit quality and increase production. This, in turn, gives them a competitive edge in attracting buyers.

\section{Conclusions and recommendations}

In order to address the challenge of food and nutrition security, investments in post-harvest food losses have to be addressed by investing in pre-harvest agricultural practices. This study aimed at identifying the factors influencing the probability and intensity of adoption of the PHPs by smallholder mango farmers in Embu and Machakos counties, Kenya. MVP and ordered probit regression models were used.

The MVP results showed that there were complementarities among the PHPs in that adoption of one PHP affected the adoption of another one. Firstly, this signifies that a policy change that affects one PHP could have spill-over effects on other PHPs. Secondly, this result implies the importance of promoting their adoption as a package, given their synergetic effects, since partial adoption may fail to achieve the desired results. The region, years of farming experience, off-farm income, number of mango trees, intercropping, access to extension services and farmers' perceptions were the main determinants of adoption of individual practices.

An OPM was used to assess the intensity of adoption of PHPs. The marginal effects showed that the following factors increased the probability of adopting more than two 
PHPs: yield perception, fruit quality perception, off-farm income, mango revenue, livestock ownership, and distance to market. However, dependency ratio, region, and constraints to input access decreased the probability of adopting more than two PHPs.

The stakeholders in the mango value chain ought to focus on strengthening the capacity of farmers to adopt more PHPs for enhanced mango production through extension services and training. The positive influence of access to off-farm income on the adoption of PHPs raises the need for more capital by the farmers to facilitate the purchasing of required inputs. Although increasing off-farm income might not be a feasible solution, introducing policies that enhance farmers' access to credit would go a long way in facilitating the adoption of the PHPs, thus leading to increased yields and farm income. The positive influence of farmer's perceptions on the adoption of PHPs stresses the need to strengthen these perceptions through knowledge transmission to farmers.

Farmers need help to overcome financial and information barriers that are crucial in enhancing the adoption of PHPs. Barriers to inputs access, majorly high costs, ought to be addressed, as well as encouraging livestock ownership which offers manure and compliments household income. Also, farmers in Embu County require more support in terms of access to extension services and training on PHPs since they were shown to have lower adoption rates.

\section{References}

Affognon, H., Mutungi, C., Sanginga, P. and Borgemeister, C. (2013) 'Unpacking postharvest losses in Sub-Saharan Africa: a meta-analysis', World Development, Vol. 66, pp.49-68.

Arslan, A., McCarthy, N., Lipper, L., Asfaw, S. and Cattaneo, A. (2013) 'Adoption and intensity of adoption of conservation farming practices in Zambia', Agriculture, Ecosystems \& Environment, Vol. 187, pp.72-86.

Chowdhury, M.N.A. and Rahim, M.A. (2007) 'Effect of fertilizers on the incidence of anthracnose disease, yield and quality of mango', J. Agric. Rural Dev., Vol. 5, pp.70-78.

Engels, C., Knödler, M., Zhao, Y., Carle, R., Gänzle, M.G. and Schieber, A. (2009) 'Antimicrobial activity of gallotannins isolated from mango (Mangifera indica L.) kernels', J. Agric. Food Chem., Vol. 57, No. 17, pp.7712-7718.

FAO (2011) Global Food Losses and Food Waste - Extent, Causes and Prevention, Rome.

FAO (2018) Transforming Food and Agriculture to Achieve the SDGs, Rome.

Ferguson, I., Volz, R. and Woolf, A. (1999) 'Pre-harvest factors affecting physiological disorders of fruit', Postharvest Biology and Technology, Vol. 15, No. 3, pp.255-262 [online] https://doi.org/10.1016/S0925-5214(98)00089-1.

Ferguson, I.B. and Boyd, L.M. (2002) 'Inorganic nutrients and fruit quality', in Knee, M. (Ed.): Fruit Quality and its Biological Basis, pp.15-45, Sheffield Academic Press, England.

Fiaz, M., Malik, A.U., Amin, M., Khan, A.S., Rehman, A., Alam, M.W. and Johnson, P. (2016) 'Production locality influences postharvest disease development and quality in mangoes', Acta Horticulturae, Vol. 1111, pp.369-376 [online] https://doi.org/10.17660/ActaHortic. 2016.1111.53.

Florkowski, W.J., Prussia, S.E., Shewfelt, R.L. and Brueckner, B. (2009) Postharvest Handling, a Systems Approach, 2nd ed., 640p, Elsevier, Academic Press, San Diego, USA.

Gebremariam, G. and Wünscher, T. (2016) 'Combining sustainable agricultural practices pays off: evidence on welfare effects from northern Ghana', African Journal of Agricultural and Resource Economics, Vol. 11, pp.1-37.

Greene, W.H. (2008) Econometric Analysis, 7th ed., Prentice Hall, New Jersey. 
Gujarati, N. (2006) Basic Econometrics, 3rd ed., McGraw Hill Book Company, New York.

Hewett, E.W. (2006) 'An overview of pre-harvest factors influencing post-harvest quality of horticultural products', International Journal of Postharvest Technology and Innovation, Vol. 1, No. 1, p.4.

Manganaris, G. (2008) 'Effect of pre-harvest and post-harvest conditions and treatments on plum fruit quality', CAB Reviews: Perspectives in Agriculture, Veterinary Science, Nutrition and Natural Resources, Vol. 3, No. 9 [online] https://doi.org/10.1079/PAVSNNR20083009.

Maqbool, M. and Mazhar, M.S. (2007) 'Pre-harvest management of mango for quality', Proceeding International Symposium on Prospects of Horticultural Industry in Pakistan, pp.111-114.

Marenya, P.P. and Barrett, C.B. (2007) 'Household-level determinants of adoption of improved natural resources management practices among smallholder farmers in western Kenya', Food Policy. Vol. 32, pp.515-536.

Marenya, P.P. and Barrett, C.B. (2007) 'Household-level determinants of adoption of improved natural resources management practices among smallholder farmers in western Kenya', Food Policy, Vol. 32, No. 4, pp.515-536.

Meijer, S.S., Catacutan, D., Ajayi, O.C., Sileshi, G.W. and Nieuwenhuis, M. (2015) 'The role of knowledge, attitudes and perceptions in the uptake of agricultural and agroforestry innovations among smallholder farmers in Sub-Saharan Africa', International Journal of Agricultural Sustainability, Vol. 13, No. 1, pp.40-54.

Mignouna, B., Manyong, M., Rusike, J., Mutabazi, S. and Senkondo, M. (2011) 'Determinants of adopting imazapyr-resistant maize technology and its impact on household income in western Kenya', AgBioforum, Vol. 14, No. 3, pp.158-163.

Mwangi, M. and Kariuki, S. (2015) 'Factors determining adoption of new agricultural technology by smallholder farmers in developing countries', Journal of Economics and Sustainable Development, Vol. 6, No. 3, pp.208-216.

Rehman, A., Malik, A.U., Ali, H., Alam, M.W. and Sarfraz, B. (2015) 'Preharvest factors influencing the postharvest disease development and fruit quality of mango', Journal of Environmental and Agricultural Sciences, Vol. 3, pp.42-47.

Reimer, A.P., Weinkauf, D.K. and Prokopy, L.S. (2012) 'The influence of perceptions of practice characteristics: an examination of agricultural best management practice adoption in two Indiana watersheds', Journal of Rural Studies, Vol. 28, No. 1, pp.118-128.

Republic of Kenya (2016) Horticulture Validated Report 2015-2016, Nairobi.

Sheahan, M. and Barrett, C.B. (2014) Understanding the Agricultural Input Landscape in Sub-Saharan Africa: Recent Plot, Household, and Community-Level Evidence, Policy Research Working Paper No. 7014, Washington, DC, World Bank.

Teklewold, H., Kassie, M. and Shiferaw, B. (2013) 'Adoption of multiple sustainable agricultural practices in rural Ethiopia', Journal of Agricultural Economics, Vol. 64, No. 3, pp.597-623 [online] https://doi.org/10.1111/1477-9552.12011.

Thompson, A.K. (2007) 'Pre-harvest factors on postharvest life', in Fruit and Vegetables, pp.1-8, Blackwell Publishing Ltd., Oxford, UK [online] https://doi.org/10.1002/9780470751060.ch1.

Wollni, M., Lee, D.R. and Thies, J.E. (2010) 'Conservation agriculture, organic marketing, and collective action in the Honduran hillsides', Agricultural Economics, Vol. 41, Nos. 3-4, pp.373-384 [online] https://doi.org/10.1111/j.1574-0862.2010.00445.x.

World Bank (2011) Missing Food: the Case of Postharvest Grain Losses in Sub-Saharan Africa, $116 \mathrm{p}$, The World Bank, Washington, DC. 